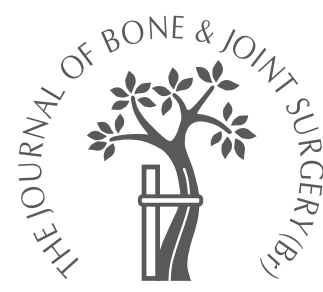

K. E. Dreinhöfer, J.-M. Féron,

A. Herrera, R. Hube, O. Johnell, L. Lidgren, K. Miles, L. Panarella, H. Simpson,

W. A. Wallace

From the Bone and Joint Decade and the International Osteoporosis Foundation

K. E. Dreinhöfer, MD, Deputy Head

Department of Orthopaedics, Rabilitationskrankenhaus, Ulm University, Oberer Eselsberg 45, 89081 Ulm, Germany.

J.-M. Féron, MD, Professor, Chef de Service

Service de Chirurgie

Orthopedique et Traumatologique

Hopital Tenon, 4 rue de la Chine,

75970 Paris, France.

A. Herrera, MD, PhD, Professor,

Chief

Service of Orthopaedic Surgery and Trauma, University Hospit "Miguel Servet", $\mathrm{P}^{\circ}$ Isabel la Católica 1-3, 5009 Zaragoza, Spain.

R. Hube, MD, PhD, Professor Department of Orthopaedic

Surgery, Martin-Luther-University, Magdeberge Strasse 22, 06122 Halle, Germany.

O. Johnell, MD, PhD, Professor Department of Orthopaedics, Malmö General Hospital, 20520 Malmö, Sweden.

L. Lidgren, MD, PhD, Professor, Head of the Department Department of Orthopaedics, Lund University, 22185 Lund, Sweden.

K. Miles, BSc, Chief Executive New Zealand Orthopaedic Association, 43 Kent Terrace Wellington, New Zealand.

L. Panarella, MD

L. Panarella, MD

Surgery, University of Rome, "Tor

Vergata", 130, Via Chiala, 00139

Rome, Italy.

H. Simpson, FRCS, Professor of Orthopaedics and Trauma University of Edinburgh, Royal Infirmary of Edinburgh Royal Infirmary of Edinburgh at Edinburgh EH16 4SU, UK.

W. A. Wallace, FRCS, FRCS ED Orth), Professor of Orthopaedics and Trauma

University Hospital, Queen's Medical Centre, Nottingham NG7 2UH, UK.

Correspondence should be sent to Dr K. E. Dreinhöfer.

(C2004 British Editorial Society of Bone and Joint Surgery

doi:10.1302/0301-620X.86B7.1532

$J$ Bone Joint Surg $[\mathrm{Br}]$

2004;86-B:958-61.

- ANNOTATION

\title{
Orthopaedic surgeons and fragility fractures
}

\author{
A SURVEY BY THE BONE AND JOINT DECADE AND THE \\ INTERNATIONAL OSTEOPOROSIS FOUNDATION
}

Osteoporosis is a "progressive skeletal disease characterized by low bone mass and microarchitectural deterioration, with a consequent increase in bone fragility and susceptibility to fracture". "The clinical relevance of osteoporosis is the resulting fractures that occur in the weakened bone - the so-called fragility fractures. Although managing the initial fractures, orthopaedic surgeons are missing a major opportunity to prevent future fractures by not providing appropriate care themselves and by instigating appropriate protocols of care to be provided by their colleagues.

Clinical trials have demonstrated that medical treatment given to patients with fragility fractures can reduce the risk of future such injuries by up to $50 \% .^{2-4}$ In a 1998 editorial, 'Fracture care is not enough', Tosi and Lane ${ }^{5}$ in the American volume of the Journal of Bone and Joint Surgery stated "We must thrive to prevent fractures rather than treating them once they occur". In a recent review in the British volume it was stated that "with such a large and diverse list of risk factors to recall when reviewing a patient with a simple insufficiency fracture in a busy clinic, it is easy to dismiss the underlying cause and simply 'treat the fracture'."6 The reasons for such neglect are related to the availability of time and resources. There has also been a lack of simple algorithms and protocols for treating the disease. Recent articles suggest that orthopaedic surgeons are still neglecting to identify, evaluate and treat patients with osteoporosis who are admitted with low-energy fractures. ${ }^{7-17}$

\section{Why we have to change this now?}

Fractures related to osteoporosis are common. Every second woman and every third man over the age of 50 will eventually suffer from an osteoporosis-related fracture. The lifetime risk for an osteoporotic fracture of the hip, spine or wrist has been reported to be $40 \%$ for Caucasian women in Europe. ${ }^{18-20}$ The risk for a hip fracture is between $11 \%$ and $18 \%$ in women, which is equal to the combined risk for breast, uterine, and ovarian cancers. ${ }^{21}$ Vertebral frac- tures are between two and three times more prevalent than those in the hip but only onethird are ever diagnosed. ${ }^{22}$ In the US alone, 1.5 million fractures, including 250000 of the hip, 250000 of the distal radius and 700000 of the vertebrae occur each year secondary to osteoporosis. $^{23}$ In the UK over 300000 osteoporotic fractures are sustained each year. ${ }^{24}$ In Germany 130000 fractures of the hip were operated on in $1999 .^{25}$ The European Parliament Osteoporosis Interest Group found that 480000 fractures of the hip had occurred in the European Union in $1999 .{ }^{26}$

The number of hip fractures is expected to increase dramatically. The number of individuals over 65 years of age is expected to almost double by the year 2040 and as the population ages, the number of hip fractures is predicted to rise dramatically. ${ }^{25}$ In 1990 , the estimated total number of these injuries in persons over the age of 50 was 1.7 million worldwide. ${ }^{27}$ Assuming that there are no changes in the ageand sex-specific incidence, the number of such fractures is estimated to reach 6.3 million worldwide by 2050 and in Europe the number will double in 50 years and exceed $970000 .^{27}$ This increase can be explained primarily by the aging of the population, and it is based on the assumption that no major changes will occur in the health of elderly people or in the prevention of these fractures. As the cost of treating these patients will also rise, a three- to eightfold increase of the overall expenditure by the year 2030 can be expected. ${ }^{28}$ The projected total costs are expected to be US $\$ 131.5$ billion worldwide by $2050 .^{29}$

Osteoporotic fractures are associated with an increase in morbidity and mortality. The negative impact on quality of life after a hip or vertebral fracture is a major concern. Up to a third of patients who sustain fracture of the hip will die as a result, ${ }^{30} 4 \%$ die during their initial hospitalisation $^{31}$ and $10 \%$ to $24 \%$ within the first year. ${ }^{32,33}$ In addition to mortality, these fractures are associated with substantial morbidity and loss of function. Half of these patients do not regain their previous level of 
mobility. They may become severely handicapped, unable to walk unaided or climb stairs and $25 \%$ will require longterm residential care. ${ }^{34}$ Many patients lose their ability to live independently and often depend on other family members for support. The annual cost of treating patients with fractures of the hip in the US is between $\$ 10.3$ and $\$ 15.2$ billion. ${ }^{35}$ The annual cost in the UK now exceeds $£ 800$ million. ${ }^{36}$ The costs to patients, family members and society occurring because of lifestyle changes and lost productivity are not known.

A fragility fracture is the strongest indicator of risk of future fracture. Patients who have had a fracture at any site have approximately twice the risk of sustaining a future fracture compared with individuals who have never experienced such an injury as an adult. ${ }^{37,38}$ Patients with a low-energy fracture of the wrist, hip, proximal humerus or ankle have nearly a fourfold greater risk for future fractures than individuals who have not. ${ }^{38} \mathrm{Up}$ to $50 \%$ of patients with a vertebral fracture will experience additional vertebral fractures within three years, many within the first year. ${ }^{39,40}$ A patient with a vertebral fracture has nearly a fivefold increased risk of a future similar injury and double the risk of hip and other non-vertebral fractures. ${ }^{37,41}$

Patients who have sustained a fracture of the distal radius have nearly twice the relative risk of a future hip fracture, ${ }^{35,42}$ and have both site-specific and generalised decreased bone-mineral density when compared with young adults and age-matched controls. ${ }^{43,44}$ Fractures of the distal radius start to occur approximately 15 years earlier than those in the hip and warn of a high risk of these latter fractures. Fractures of the distal radius are therefore good indicators for investigation of osteoporosis. In a cohort of 22494 low-energy fractures, the relative risk of a fracture of the hip following a fracture of the wrist, proximal humeral, ankle or hip was 3.22, 5.76, 1.30 and 9.79, respectively. ${ }^{38} \mathrm{~A}$ contralateral hip fracture may occur in as many as $10.6 \%$ of patients with a fracture at the hip. ${ }^{45}$

The majority of patients with fragility fractures are discharged without adequate evaluation of osteoporosis. Despite the evidence in support of appropriate management of patients with osteoporosis after they have sustained a fragility fracture, up to $95 \%$ are discharged without adequate assessment as to the cause of the fracture and very few are prescribed medication. ${ }^{7-17}$

Gardner et $\mathrm{al}^{10}$ retrospectively analysed 300 randomly selected patients with fractures of the femoral neck. Only $58(19.3 \%)$ had received a prescription for medication targeting osteopenia at the time of their discharge. However, 40 of these patients ( $13.3 \%$ of the overall group) had been prescribed calcium but only 18 (6.0\% of the overall group) had received medication to actively prevent bone resorption and to treat osteoporosis. The remaining $81 \%$ of patients were discharged without proper medication and none had a bone density scan while in hospital. ${ }^{10}$

Freedman et $\mathrm{al}^{9}$ analysed 1164 patients with fractures of the distal radius and found that few had been assessed or treated for osteoporosis. Only $2.8 \%$ had been tested for bone density, and only $22.9 \%$ were treated with at least one of the drugs approved for managing established osteoporosis. ${ }^{9}$ Torgerson and Dolan ${ }^{17}$ found that, following an osteoporotic fracture, the majority of patients were not prescribed any suitable medication. Only $39 \%$ of patients with vertebral fractures received antiresorptive medication, and patients with fractures of the hip did not receive any. ${ }^{17}$ A survey of 56 Danish departments of orthopaedic surgery showed that only seven $(12.5 \%)$ referred their patients with a low-energy fracture for a bone density scan and only six $(10.7 \%)$ gave treatment for those with osteoporosis. ${ }^{46}$

\section{Multinational survey}

The Bone and Joint Decade and the International Osteoporosis Foundation (IOF) initiated a multinational survey of the current care of patients with osteoporotic fractures in a range of countries with different health care systems (UK, Germany, Spain, Italy, France and New Zealand) in order to assess the levels of practice.

In association with the respective societies (BOA, DGOOC, SECOT, SIOT, SOFCOT and NZOT), a working group of national project coordinators was convened and a questionnaire developed, partly based on an American survey in $2000 .{ }^{47}$ This questionnaire was then translated into the national language. The national project coordinator determined the optimum method of distributing the survey. Anonymous responses were collected nationally and then analysed centrally. ${ }^{48}$

Results. Overall 3422 surgeons responded, representing approximately $25 \%$ of all society members. The response rate was highest in New Zealand $(70 \%)$. Although a higher overall multinational response rate would have allowed a more accurate appraisal, the results provide valuable insights into the current state of practice.

The survey reflects the opinion of surgeons, who each month treat at least 54000 fragility fractures in their units, and prescribe medication for osteoporosis for 30000 patients per month.

In all countries, the majority of respondents believed that the orthopaedic surgeon should identify and initiate the evaluation of osteoporosis in patients with fragility fractures. However, only $10 \%$ always initiated a bone density test after surgically treating a patient for a fragility fracture. If osteoporosis is suspected, most surgeons in France, the UK and New Zealand $(70 \%$ to $90 \%)$ would refer the patient to an osteoporosis specialist or general practitioner, while more than $80 \%$ of those in Germany and Italy initiate investigation and treatment themselves.

More than half of the orthopaedic surgeons surveyed said they had received no or insufficient education in osteoporosis. In Italy and Spain this was lower but a third still felt that they were inadequately informed.

Only $25 \%$ of the orthopaedic surgeons in France, the UK and NZ felt well informed about managing osteoporosis, while more than $80 \%$ in Germany and Spain were confi- 
dent in their knowledge. Most of the surgeons in Germany, Italy and Spain felt competent in prescribing calcium/vitamin D and bisphosphonates, compared to less than $50 \%$ of their colleagues in France, the UK and New Zealand. Only $50 \%$ of orthopaedic surgeons in Southern Europe knew about the importance of external risk factors for hip fractures such as a cataract, poor lighting, uneven carpets and poor balance. There were also a number of misconceptions about the indications for bone mineral density in the countries (Germany, Spain) where surgeons considered themselves knowledgeable about osteoporosis.

The majority of surgeons from all countries recommended that a baseline bone density test should be performed in a woman aged 50 without risk factors or fracture, indicating a lack of knowledge about the current indications for bone mineral density testing.

Clearly there is a need for further education and improved training. Fortunately, the majority of orthopaedic surgeons in all countries were interested in learning more about the diagnosis and management of osteoporosisrelated fractures. The mode of learning which most surgeons preferred was through seminars or journals, followed by $\mathrm{CD}$ ROMs and website based information. E-based learning was the most popular in France. There was very little interest (less than $15 \%$ ) by orthopaedic surgeons in all countries receiving direct information from pharmaceutical representatives.

There is a need for orthopaedic surgeons to be more aware of the concerns of their patients regarding osteoporosis. The National Osteoporosis Society was wellknown in only two of the countries (UK and Germany). In the remainder more than half of the surgeons had not heard about their National Osteoporosis Society.

This survey suggests that current practice is inadequate for the diagnosis and treatment of osteoporosis, especially in patients who have sustained a fragility fracture. We are aware that there may be a selection bias in the study since the surgeons who answered have already positively selected themselves, and therefore the lack of knowledge about osteoporosis is probably underestimated.

Patients with fractures create a unique opportunity for treatment since the optimal care of fragility fractures includes fixing the fracture and the evaluation, diagnosis and treatment of its underlying cause. ${ }^{49}$ Pharmacological intervention has the potential to reduce the risk of future fracture by half in patients with existing fractures. Other measures such as fall prevention and individually-tailored exercise programmes have been shown to reduce falls among the elderly. ${ }^{4}$

\section{How to improve care for the patient with osteoporosis}

Awareness. It is now recognised that insufficient priority is given to osteoporosis and the fractures it causes. The adherence to currently existing guidelines is not known, but is probably low. The outcome of surgical procedures should be followed on a large scale through appropriate audit studies to evaluate the standard of care. Fracture registries could monitor the size of the problem, assess the success of treatment and assist in planning adequate provision of resources. Additional awareness and general education programmes for orthopaedic surgeons and patients need to be established.

Research. Research into better methods of managing these demanding fractures are needed to cope with the inevitable rise in their incidence and the surgical challenges which they pose. We need to improve further pharmacological and general management with strategies for primary and secondary prevention. We need to develop new surgical and/or biological techniques of repair for treating osteoporotic fractures. ${ }^{50}$

Education. Most orthopaedic surgeons felt that their education in osteoporosis was deficient. This needs to be improved in those surgeons already practising and additional emphasis on these disorders needs to be introduced into university and postgraduate training. In a recent report, the World Orthopaedic Osteoporosis Organisation (WOOO) has summarised its "Recommendations for Care of the Osteoporotic Fracture Patient to Reduce the Risk of Future Fracture", and developed a clinical pathway to ensure that optimal care is provided for patients with fragility fractures. ${ }^{3}$ The prevention of further fractures is based on three aspects: 1 ) the treatment of osteoporosis; 2) prevention of falls and 3) protection of the site of injury e.g. with hip protectors. These recommendations and the clinical pathway provide a useful resource for national orthopaedic associations to adapt for local use and implementation. This has already happened in the UK with the new booklet on "The Care of Fragility Fracture Patients" produced by the British Orthopaedic Association. ${ }^{51}$ Orthopaedic surgeons have to ensure that every patient with a fragility fracture has the appropriate operative treatment and appropriate evaluation, treatment and advice for the underlying disease so that they are aware of the further risks and the opportunities to reduce them.

Service provision and further development. Each centre should guarantee that adequate access to measurements of $\mathrm{BMD}$ is available. A multidisciplinary meeting to agree on a standard protocol for the management of known osteoporosis both in pharmacological and general terms should be arranged.

The concept of a fracture liaison nurse has been introduced with much success in several countries. The major role is to coordinate and develop productive working relationships with the diverse teams of healthcare professionals needed to ensure that the patient receives appropriate treatment and care in addition to the management of the fracture. $^{52}$

Every patient should receive an appropriate and technically satisfactory operation and be evaluated and treated appropriately for the underlying disease. They should be 
advised as to their susceptibility to falls and of the changes in lifestyle which will help prevent future fractures.

In a number of countries "Care Pathways", blueprints of the standard management of common conditions are being developed. It is hoped that this study combined with the WOOO Guidelines will allow each hospital involved to develop a "Fracture Care Pathway" which will include the treating surgeon, nursing and theatre staff, the general practitioner (Family Doctor), the social worker and the physicians providing the local "Bone Treatment management" and the "Falls Prevention Service". By developing this care pathway we will reduce the number of patients returning to us with further fractures in the future, and thus reduce the deaths and severe disabilities which are a consequence.

\section{References}

1. Consensus development conference diagnosis, prophylaxis, and treatment of osteoporosis. Am J Med 1993;94:646-50.

2. Delmas PD. Treatment of postmenopausal osteoporosis. Lancet2002;359:2018-26.

3. Bouxsein ML, Kaufman J, Tosi L, et al. Recommendations for optimal care of the fragility fracture patient to reduce the risk of future fractures. J Am Acad Orthop Surg 2004:in press.

4. Woolf AD, Akesson K. Preventing fractures in elderly people. BMJ 2003;327:89-95

5. Tosi L, Lane JM. Osteoporosis prevention and the orthopaedic surgeon: when fracture care is not enough. J Bone Joint Surg [Am] 1998;80-A:1567-9.

6. Stephen AB, Wallace WA. The management of osteoporosis. J Bone Joint Surg [Br] 2001;83-B:316-23.

7. Bellantonio S, Fortinsky R, Prestwood K. How well are community-living women treated for osteoporosis after hip fracture: J Am Geriatr Soc 2001;49-9:1197-204.

8. Castel H, Bonneh DY, Sherf M, Liel Y. Awareness of osteoporosis and compliance with management guidelines in patients with newly diagnosed low-impact fractures. Osteoporos Int 2001;12:559-64.

9. Freedman KB, Kaplan FS, Bilker WB, Strom BL, Lowe RA. Treatment of osteoporosis: are physicians missing an opportunity? J Bone Joint Surg [Am] 2000;82-A 1063-70.

10. Gardner MJ, Flik KR, Mooar P, Lane JM. Improvement in the undertreatment of osteoporosis following hip fracture. J Bone Joint Surg [Am] 2002;84-A:1342-8.

11. Hajcsar EE, Hawker G, Bogoch ER. Investigation and treatment of osteoporosis in patients with fragility fractures. Cmaj 2000;163:819-22.

12. Harrington JT, Broy SB, Derosa AM, Licata AA, Shewmon DA. Hip fracture patients are not treated for osteoporosis: a call to action. Arthritis Rheum 2002;47: 651-4.

13. Juby AG, De Geus-Wenceslau CM. Evaluation of osteoporosis treatment in seniors after hip fracture. Osteoporos Int 2002;13:205-10.

14. Khan SA, de Geus C, Holyroyd B, Russell AS. Osteoporosis follow-up after wrist fractures following minor trauma. Arch Intern Med 2001;161:1309-12.

15. Kiebzak GM, Beinart GA, Perser K, et al. Undertreatment of osteoporosis in men with hip fracture. Arch Intern Med 2002;162:2217-22.

16. Simonelli C, Chen YT, Morancey J, Lewis AF, Abbott TA. Evaluation and management of osteoporosis following hospitalization for low-impact fracture. J Gen Intern Med 2003;18:17-22.

17. Torgerson DJ, Dolan P. Prescribing by general practitioners after an osteoporotic fracture. Ann Rheum Dis 1998;57:378-9.

18. Kanis JA, Johnell $\mathbf{0}$, Oden $\mathbf{A}$, et al. Long-term risk of osteoporotic fracture in Malmo. Osteoporos Int 2000;11:669-74.

19. Melton LJ 3rd, Chrischilles EA, Cooper C, Lane AW, Riggs BL. Perspective: how many women have osteoporosis? J Bone Miner Res 1992;7:1005-10.

20. Lauritzen JB, Schwarz P, Lund B, McNair P, Transbol I. Changing incidence and residual lifetime risk of common osteoporosis-related fractures. Osteoporos Int 1993; 3:127-32

21. Cooper C. The crippling consequences of fractures and their impact on quality of life. Am J Med 1997;103:12-17

22. Gehlbach SH, Bigelow C, Heimisdottir M, et al. Recognition of vertebral fracture in a clinical setting. Osteoporos Int 2000;11:577-82
23. Riggs BL, Melton LJ III. The worldwide problem of osteoporosis: insights afforded by epidemiology. Bone 1995;17(Supp 5):505-11

24. Jordan KM, Cooper C. Epidemiology of osteoporosis. Best Pract Res Clin Rheumatol 2002;16:795-806.

25. Wildner M, Clark DE. Hip fracture incidence in East and West Germany: reassessment ten years after unification. Osteoporos Int 2001;12:136-9.

26. International Osteoporosis Foundation. Osteoporosis in the European community: a call to action: an audit of policy developments since 1998, 2001. http://www.osteofound.org/advocacy_policy/eu_calltoaction_report.html (accessed 25/05/04).

27. Cooper C, Campion G, Melton LJ 3rd. Hip fractures in the elderly: a world-wide projection. Osteoporos Int 1992;2:285-9.

28. Cummings SR, Rubin SM, Black D. The future of hip fractures in the United States: numbers, costs, and potential effects of postmenopausal estrogen. Clin Orthop 1990; 252:163-6.

29. Johnell $\mathbf{0}$. The socioeconomic burden of fractures: today and in the 21 st century Am J Med 1997;103:20-5.

30. Keene GS, Parker MJ, Pryor GA. Mortality and morbidity after hip fractures. BMJ 1993;307:1248-50.

31. Magaziner J, Lydick E, Hawkes W, et al. Excess mortality attributable to hip fracture in white women aged 70 years and older. Am J Public Health 1997;87:1630-6.

32. Center JR, Nguyen TV, Schneider D, Sambrook PN, Eisman JA. Mortality after all major types of osteoporotic fracture in men and women: an observational study. Lancet 1999;353:878-82

33. Cauley JA, Thompson DE, Ensrud KC, Scott JC, Black D. Risk of mortality following clinical fractures. Osteoporos Int 2000;11:556-61.

34. Cree M, Soskulne CL, Belseck E, et al. Mortality and institutionalization following hip fracture. J Am Geriatr Soc 2000;48:283-8.

35. Cummings SR, Nevitt MC, Browner WD, et al. Risk factors for hip fracture in white women. N Engl J Med 1995;332:767-73.

36. Melton LJ 3rd. Adverse outcomes of osteoporotic fractures in the general population. J Bone Miner Res 2003;18:1139-41.

37. Klotzbuecher CM, Ross PD, Landsman PB, Abbott TA 3rd, Berger M. Patients with prior fractures have an increased risk of future fractures: a summary of the literature and statistical synthesis. J Bone Miner Res 2000;15:721-39.

38. Robinson CM, Royds M, Abraham A, et al. Refractures in patients at least fortyfive years old: a prospective analysis of twenty-two thousand and sixty patients J Bone Joint Surg [Am]2002;84-A:1528-33.

39. Nevitt MC, Ross PD, Palermo L, et al. Association of prevalent vertebral fractures bone density, and alendronate treatment with incidence vertebral fractures: effect of number and spinal location of fractures. Bone 1999;25:613-19.

40. Lindsay R, Silverman SL, Cooper C, et al. Risk of new vertebral fracture in the year following a fracture. JAMA 2001;285:320-3.

41. Gunnes $\mathbf{M}$, Mellstrom $\mathbf{D}$, Johnell $\mathbf{0}$. How well can a previous fracture indicate a new fracture? a questionnaire study of 29,802 postmenopausal women. Acta Orthop Scand 1998;69:508-12

42. Mallmin H, Ljunghall S, Persson I, et al. Fracture of the distal forearm as a forecaster of subsequent hip fracture: a population-based cohort study with 24 years of follow-up. Calcif Tissue Int 1993;52:269-72.

43. Mallmin H, Ljunghall S, Persson I, Bergstrom R. Risk factors for fractures of the distal forearm: a population-based case-control study. Osteoporos Int 1994:4 298-304.

44. Earnshaw SA, Cawte SA, Worley A, Hosking DJ. Colles' fracture of the wrist as an indicator of underlying osteoporosis in postmenopausal women: a prospective study of bone mineral density and bone turnover rate. Osteoporos Int 1998:8:53-60.

45. Boston DA. Bilateral fractures of the femoral neck. Injury 1982;14:207-10.

46. Eiken PA. Osteoporosis: assessment, prevention and treatment in Danish depart ments of orthopedic surgery. Ugeskr Laeger 1996;158:5790-3

47. Kaufman A. A survey of orthopedic surgeons attitudes and knowledge of osteoporosis. AAOS annual meeting, poster exhibit 2000.

48. Dreinhöfer KE, Féron JM, Herrera A, et al. Survey of osteoporotic fracture management. Osteoporos Int 2004:in press

49. Rosier RN. Expanding the role of the orthopaedic surgeon in the treatment of osteoporosis. Clin Orthop 2001;385:57-67.

50. Nilsson M, Fernandez E, Sarda S, Lidgren L, Planell JA. Characterization of a novel calcium phosphate/sulphate bone cement. J Biomed Mater Res 2002;61:600-7.

51. Marsh D, Simpson H, Wallace WA. The care of fragility fracture patients. British Orthopaedic Association 2003.

52. McClellan A, Gallacher SJ, Fraser M, McQuillian C. The fracture liaison service: success of a program for the evaluation and management of patients with osteoporotic fracture. Osteoporos Int 2003;14:1028-34. 